\title{
The Future of Learning and Training in Augmented Reality
}

\author{
Kangdon Lee \\ Graduate student, Masters in Educational Technology Program \\ University of Northern Colorado
}

Students acquire knowledge and skills through different modes of instruction that include classroom lectures with textbooks, computers, and the like. The availability and choice of learning innovation depends on the individual's access to technologies and on the infrastructure environment of the surrounding community. In this rapidly changing society, information needs to be adopted and applied at the right time and right place to maintain efficiency in all settings. Augmented reality is one technology that dramatically shifts the timing and location of learning. This paper describes augmented reality, how it applies to learning, and its potential impact on future education.

\section{The General Meaning of AR}

Augmented reality (AR) is a technology that allows computer-generated virtual imagery information to be overlaid onto a live direct or indirect real-world environment in real-time (Azuma, 1997; Zhou, Duh, \& Billinghurst, 2008). AR differs from virtual reality (VR) in that VR users experience a computer-generated virtual environment, whereas in $A R$, the environment is real, but extended with information and imagery from the system. In other words, AR bridges the gap between the real and the virtual in a seamless way (Chang, Morreale, \& Medicherla, 2010). To better understand AR, two real-world examples can be taken from televised sporting events to show the basic concept of adding computer-assisted contextual layers of information over the real world, creating a reality that is enhanced or augmented. The first example is the yellow line drawn on the field of an American football game to add virtual information over the real game and show TV viewers a "magic line" that players must reach for the first down. The second example is from car racing, where an annotation provides viewers with additional information on the speed of a competing car.

\section{The Origin of AR in Learning and Training}

According to Johnson, Levine, Smith, and Stone (2010), the history of AR goes back to the 1960s, when the first system was used for both augmented and virtual reality. An optical see-through, head-mounted display was tracked by either a mechanical or an ultrasonic tracker. Due to the limited processing power of computers at that time, only very simple wire frame drawings could be displayed in real time (Sutherland, 1968). Since then, augmented reality has been put to use by a number of major companies for visualization, training, and other purposes. The term 'augmented reality' is attributed to former Boeing researcher Tom Caudell, who is believed to have coined the term in 1990.

\section{Marker- and Markerless-based AR}

According to Johnson et al. (2010), augmented reality systems can either be marker-based or markerless-based. Marker-based applications comprise three basic components that include a booklet for offering marker information, a gripper for getting information from the booklet and converting it to another type of data, and a cube for augmenting information into 3D-rendered information on a screen. On the other hand, markerless-based applications need a tracking system that involves a global positioning system (GPS), a compass, and an image recognition device instead of the three elements of marker-based systems. Markerless 
applications have wider applicability because they function anywhere without the need for special labeling or supplemental reference points.

\section{Adopting AR in Learning and Training}

According to Chang et al. (2010), several researchers have suggested that students and trainees can strengthen their motivation for learning and enhance their educational realism-based practices with virtual and augmented reality. In spite of a great amount of research during the last two decades, adopting AR in learning and training is still quite challenging because of issues with its integration with traditional learning methods, costs for the development and maintenance of the AR system, and general resistance to new technologies. Now, however, AR promises to attract and inspire learners with the exploration and control of materials from diverse perspectives that have not been taken into consideration in real life; AR in education

...AR has the potential to further engage and motivate learners in discovering resources and applying them to the real world from a variety of diverse perspectives that have never been implemented in the real world. and training is thus believed to have a more streamlined approach with wider user adoption than ever before, due to the improvements in computer and information technology. Kerawalla, Luckin, Seljeflot, and Woolard (2006) stated that even though many AR applications have been developed for educational and training purposes since the advent of $A R$ in the late 1960s, AR's potential and pragmatic employment has just begun to be explored and utilized in real life. He emphasized that AR has the potential to further engage and motivate learners in discovering resources and applying them to the real world from a variety of diverse perspectives that have never been implemented in the real world.

\section{How AR Applies to Learning and Training}

Johnson et al. (2010) stated that "AR has strong potential to provide both powerful contextual, on-site learning experiences and serendipitous exploration and discovery of the connected nature of information in the real world" (p. 21). AR has been experimentally applied to both school and business environments, although not as much as classic methods of learning and training during the last two decades. In addition, now that the technologies that make augmented reality possible are much more powerful than ever before and compact enough to deliver AR experiences to not only corporate settings but also academic venues through personal computers and mobile devices, several educational approaches with AR technology are more feasible. Also, wireless mobile devices, such as smart phones, tablet PCs, and other electronic innovations, are increasingly ushering in this technology, AR, into the mobile space where the AR applications offer a great deal of promise, especially in learning and training.

\section{AR in School}

Professionals and researchers have striven to apply AR to classroom-based learning in subjects like chemistry, mathematics, biology, physics, astronomy, and other K-12 education or higher, and to adopt it into augmented books and student guides. However, Shelton (2002) estimated that AR has not been much adopted into academic settings due to insufficient funding by the government and lack of awareness regarding the needs for AR in academic settings. 


\section{AR in Business}

In corporate venues, AR is a collaborative, skill-learning, explainable, and guidable tool for workers, managers, and customers. Additionally, businesses have better environments than those of educational settings for maintaining the costs and support of AR applications. Many corporations are interested in employing AR for the design and the recognition of their products' physical parts. According to the evaluation by Shelton (2002), for example, enterprises can not only imagine designing a car in 3D, in which they are able make immediate changes when needed, but can also create virtual comments explaining to the technicians what needs to be fixed.

\section{The Current Position of AR in Learning and Training}

During the last few decades, many professionals and researchers have been developing pragmatic theories and applications for the adoption of AR into both academic and corporate settings. By virtue of those studies, innovations of AR have been developed and are being used to enhance the learning and training efficiency of students and employees. In addition, a great number of studies are being conducted to improve the compatibility and applicability of AR in real life. However, according to Shelton and Hedley (2004), many questions still linger about its use in education and training, including issues of cost effectiveness, of the efficiency of AR instructional systems as compared with conventional methods, and the like.

\section{Augmented Astronomy}

In an astronomy class, students learn about the relationship between the earth and the sun. For the sake of students' understanding, educators may employ AR technology with 3D-rendered earth and sun shapes.

Shelton's (2004) study described the following:

The virtual sun and earth are manipulated on a small hand-held platform that changes its orientation in coordination with the viewing perspective of the student. The student controls the angle of viewing in order to understand how unseen elements work in conjunction with those that were previously seen ( $p .324)$.

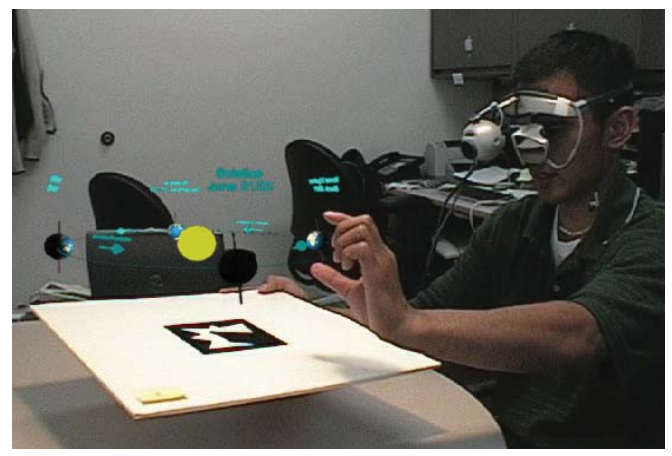

Figure 1. A view of a student interacting with real objects (foam core card, table, wall) and artificial objects (Sun, Earth, annotations) through the augmented reality interface. This view is that seen through the lens of an HMD (Shelton, 2004). 
As another example of AR's use in astronomy, Johnson et al. (2010) described Google's SkyMap as an application using AR technology. SkyMap overlays information about the stars and the constellations as users browse the sky with the see-through view from the camera on their smart phones (p. 23).

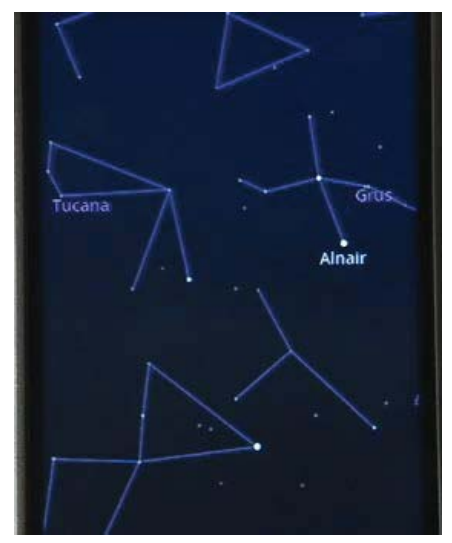

$\begin{array}{lllll}\text { Figure } 2 . & \text { Google } & \text { SkyMap } & \text { (Retrieved }\end{array}$ http://www. youtube.com/watch?v=p6znyx0gjb4).

\section{Augmented Chemistry}

Augmented chemistry is an interactive, educational workbench that can show students how and what an atom or a molecule consists of via AR. Three elements, a booklet, a gripper, and a cube, are required to implement this task with both hands. Fjeld and Voegtli (2002) said that the booklet displays components by a printed picture and a name. One hand browses the booklet with a gripper which has a button used to connect an atom to the molecular model. According to Fjeld and Voegtli (2002), users first bring the gripper around the element in the booklet and get information about the element by clicking the button of the gripper. Second, users move the gripper next to a cube, called a platform, which holds a molecule. Subsequently, by rotating a cube operated by the other hand, users can determine where and how the element connects to the molecule.

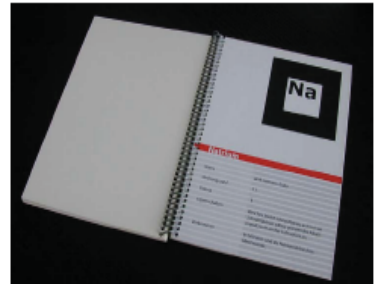

$\mathbf{a}$

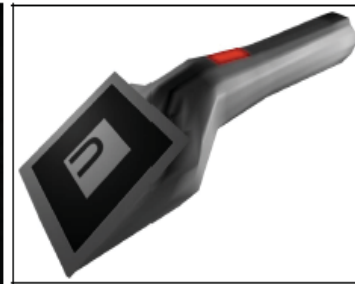

b

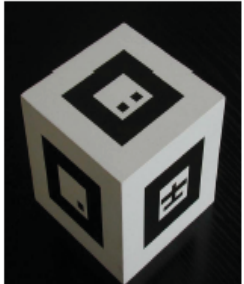

c

Figure 3. a) Booklet offering one element per page-here $\mathrm{Na}$, sodium. Each element is represented by a pattern. b) Gripper with a button (red) and a pattern. c) Cube with one distinct pattern for each surface (Fjeld \& Voegtli, 2002). 


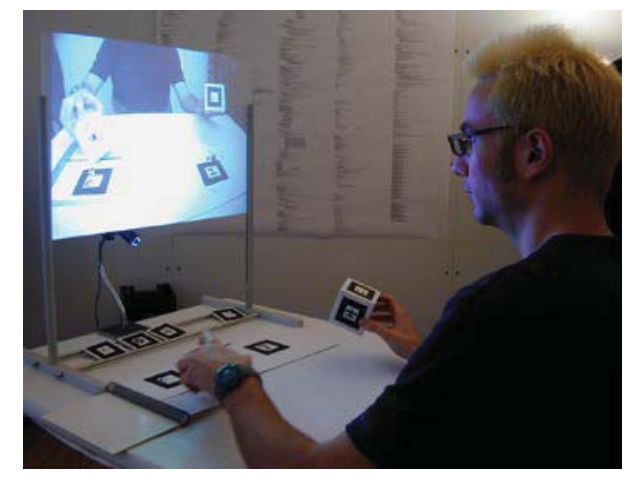

Figure 4. System set-up with a typical situation of use: charging the Gripper with an element from the booklet (left). The platform (right) holds an unsaturated atom, with which a binding with the charged atom may be triggered (Fjeld \& Voegtli, 2002).

\section{Augmented biology}

AR can be used to study the anatomy and structure of the body in biology. The Specialist Schools and Academies Trust (SSAT) demonstrated that teachers could use AR technology to show what human organs consist of and what they look like by watching 3D computer-generated models in the real classrooms. Moreover, students may be able to study human organs independently with their cameraembedded laptops and AR markers that connect PCs with AR information about biological structures of the human body. (Retrieved from https://www.ssatrust.org.uk/achievement/future/Pages/AugmentedReality.aspx)

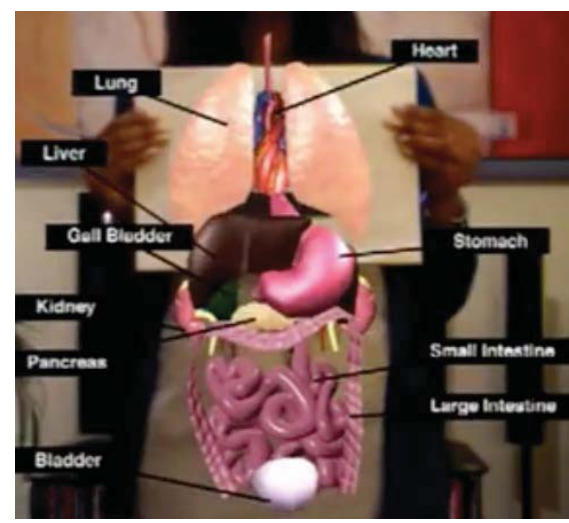

Figure 5. A model of human internal organs with AR technology that can be used in biology class (Retrieved from http://www.learner.org).

\section{Mathematics and Geometry Education}

With AR technology, teachers and students can collaborate by interacting with each other for some issues on shapes or arrangements. According to Chang et al. (2010), an AR application called Construct3D specifically designed for mathematics and geometry education with 3D geometric construction models (as 
cited in Kaufmann, 2006; Kaufmann \& Schmalstieg, 2002; Kaufmann, Schmalstieg, \& Wagner, 2000). This application allows multiple users such as teachers and students to share a virtual space collaboratively to construct geometric shapes by wearing head-mounted displays that enable users to overlay computer-generated images onto the real world.

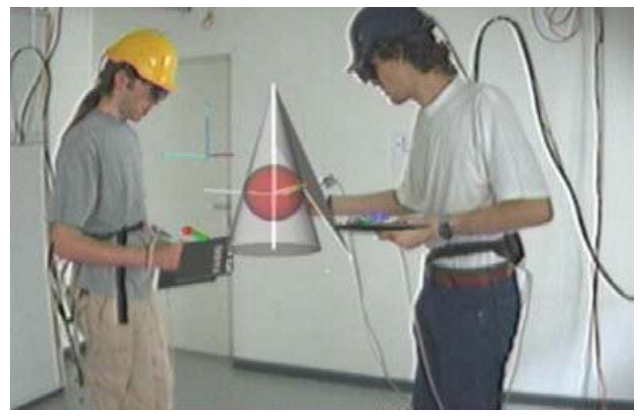

Figure 6. Students working with construct3D inscribe a sphere in a cone (Kaufmann $\&$ Schmalstieg, 2002).

Furthermore, Kaufmann (2009) determined that AR can be used in dynamic differential geometry education in a wide range of ways. For instance, using the AR application, teachers and students can intuitively explore properties of interesting curves, surfaces, and other geometric shapes.

\section{AR in K-12 Education}

Freitas and Campos (2008) developed the System of Augmented Reality for Teaching (SMART), an educational system that uses AR technology for teaching 2nd grade-level concepts, such as the various means of transportation and types of animals. This system superimposes three-dimensional models and prototypes, such as a car, truck, and airplane, on the real-time video feed shown to the whole class. Because most children spend a great deal of time playing digital games, gamebased instruction is one way to engage children in learning. Freitas and Campos (2008) performed several experiments with 54 students in three different schools in Portugal. The results of a number of studies by Freitas and Campos (2008) indicated that SMART helps increase motivation among students, and that it has a positive impact on their learning experiences, especially among those who are less academically successful.

\section{How AR is Applied to Business Training}

\section{Cultural Heritage}

From cultural and traditional perspectives, AR can be used as an influentially interactive tool in cultural heritage sites by showing visitors the original images of the sites and informing travelers of historical episodes of the places with 3D effects. Vlahakis et al. (2002) demonstrated in their research of Augmented Reality-based Cultural Heritage On-site Guide (ARCHEOGUIDE) that the AR tour assistant system provides on-site help and augmented-reality reconstructions of ancient ruins, based on the user's position and orientation in the cultural site, and real-time image rendering. ARCHEOGUIDE is based on computer and mobile technologies, including AR, 3D-visualization, mobile computing, and multi-modal interaction techniques. The equipment consists of a head-mounted display (HMD), 
an earphone, and a mobile computing unit. But other versions include a PDA or a lightweight portable computer with a simple input device. With these AR devices, individuals can visit historic sites and tour around, comparing an original image to an augmented modeling as well as viewing three-dimensional models of what the construction was and looked like in the past, and who the person was, even though the original edifice no longer exists or is in a state of ruin.

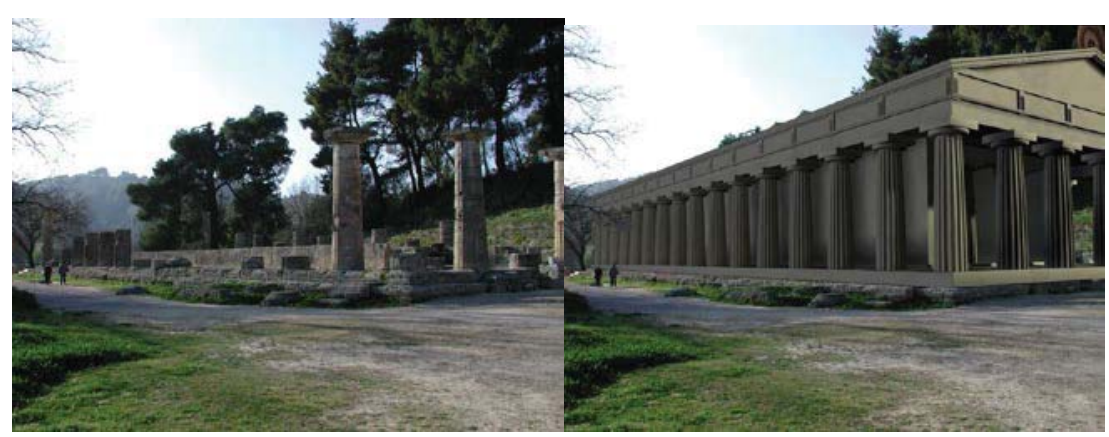

a.

b.

Figure 7. a) The original image of a heritage site b) An image of AR modeling. Examples of ARCHEOGUIDE's original image and AR modeling (Vlahakis et al., 2002).

\section{Industrial Maintenance}

In the field of industrial maintenance, AR offers very practical assistance to staff in their highly demanding technical work. Henderson and Feiner (2009) observed that corporate sectors such as military, manufacturing, and other industries are the applied fields where AR thrives in competition and expands the scope of the technology itself. According to studies (Henderson \& Feiner, 2009) that concentrate on the military sector, with the assistance of AR technology, military mechanics in particular can conduct their routine maintenance tasks in a bulletproof vehicle more safely and conveniently. To do this requires several devices and apparatuses such as a tracked head-worn display to augment a mechanic's natural view with text, labels, arrows, and animated sequences designed to facilitate task comprehension, location, and execution. 


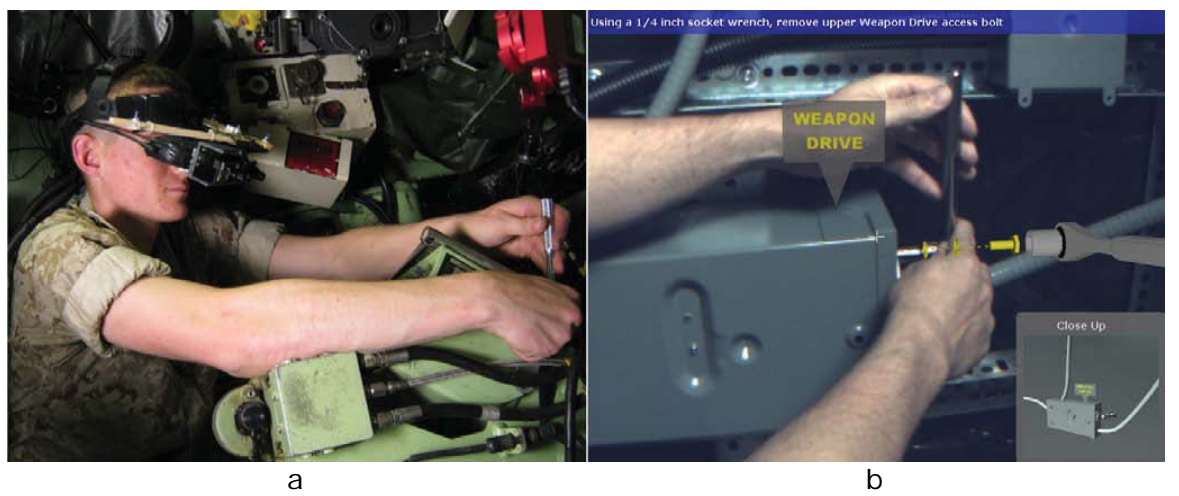

Figure 8. a) A mechanic wearing a tracked head-worn display performs a maintenance task inside an LAV-25A1 armored personnel carrier. b) The AR condition in the study: A view through the head-worn display captured in a similar domain depicts information provided using augmented reality to assist the mechanic (Henderson \& Feiner, 2009).

The same concept of using AR technology in military maintenance can be applied to manufacturing industries. A great deal of research in the field of augmented reality has been paving the way for companies to employ AR technology in their own sectors. For instance, BMW, one of the famous German motor vehicle companies, has been interested in utilizing $A R$ techniques in their car maintenance and repair divisions and has developed an AR maintenance and repair system and data glasses (Retrieved from http://www.bmw.com/ $\mathrm{com} / \mathrm{en} /$ owners/service/augmented_reality introduction 1.html). And they are just about to use contextually and interactively advanced $A \bar{R}$ technology as a means to support their service staff in their complex and technical work environments. According to BMW, technicians, wearing special data goggles and connecting to their computer servers, have all the information at their disposal, precisely where they need it: in the workplace, at the vehicle. By wearing AR glasses, for example, mechanics receive additional three-dimensional information on the part they are repairing to help them in diagnosing and solving the fault. Apart from the real environment, they see animated components about the part that needs replacing and the tools to be used, while an audio instruction talks to mechanics about each of the working steps through headphones integrated inside the goggles. 


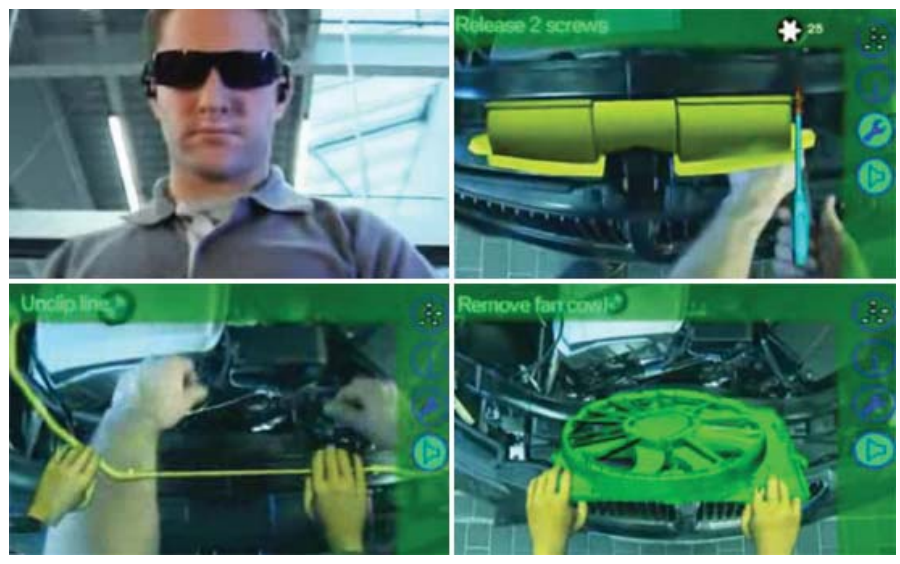

Figure 9. BMW's AR goggles and system, which assist mechanics in performing maintenance on the company's cars (BMW, 2010).

\section{Conclusion}

The future of augmented reality as a visualization technology looks bright; this is evident from the interest generated in business and industrial circles as well as discussed in popular periodicals and research papers in the learning and training fields. Many questions still linger in terms of cost-effectiveness when compared to traditional methods, particularly given the investments needed in research and design. However, there is much optimism about AR's role in learning and training for the future. New technologies and information communications are powerful and compact enough to deliver AR experiences via personal computers and mobile devices; they

AR not only has the power to engage a learner in a variety of interactive ways never possible before - it can also provide each individual with their own unique discovery path with rich content from computergenerated, threedimensional environments and models. are also sufficiently well developed and sophisticated to combine real world with augmented information in interactively seamless ways.

\section{The Future of Learning and Training with AR}

Several cutting-edge AR applications to date have been mostly developed for location-based information, social networking services, and entertainment. New $A R$ tools for other purposes such as learning and training, however, will continue to be developed as the technology evolves and becomes more advanced than ever. A considerable number of professionals and researchers from the field of learning and training science predict that simple AR applications in education will be realized within a few years.

\section{I nteractive Education}

It is highly likely that AR can and will make educational environments more productive, pleasurable, and interactive than ever before. AR not only has the power to engage a learner in a variety of interactive ways never possible before -- 
it can also provide each individual with their own unique discovery path with rich content from computer-generated, three-dimensional environments and models.

\section{Simplicity}

As shown in a great deal of previous research and professional opinion, AR could probably be focused on simplicity and ease of providing learning and training experiences, so that students and trainees can accept knowledge and skills with 3D simulations generated by computers and other electronic devices. In addition, related industries and technologies (such as computer and mobile industries, information and communication technologies, and Internet network infrastructures, including both wired and wireless services) might enable AR in learning and training to be much more straightforward and succinct to approach and utilize than ever before.

\section{Contextual I nformation}

In the view of many professionals and experts in the field of educational $A R$, it is possible that AR can improve the extent and quality of information by making learning and training environments, i.e., schools and businesses, more educational, productive, and contextual. In this perspective, there seem to be many contextual elements that could possibly be embedded in educational $A R$ applications; such elements could enhance the quality of learning and training by producing and delivering rich, constructive, and gainful content. For instance, Geo tag information for historical and cultural heritages could be connected, and annotation regarding complex physical objects and artifacts could readily be added to AR tools in both business and school venues.

\section{Efficiency and Effectiveness}

AR has the potential to promote efficiency of learning and training in academic and corporate surroundings by providing information at the right time and right place and offering rich content with computer-generated $3 D$ imagery. AR may appeal to constructivist notions of education, where students take control of their own learning, and could provide opportunities for more authentic learning and training styles. Besides, there are no real consequences in terms of dangerous and hazardous work environments if mistakes are made during skills training. As the results of several studies have shown, AR systems can provide motivating, entertaining, and engaging environments conducive to learning. In addition, AR applications in educational settings are attractive, stimulating, and exciting for students and provide cost-effective support for the users.

\section{Constraints of AR in Teaching and Training}

Despite the actual and potential advantages of using AR in teaching and training, there are a few constraints on employing AR for educational purposes. People can question the use of AR in learning and training in light of the efficiency between AR system investment and the significance of problems in both academic and corporate settings. In addition, companies or schools may have suspicions about the effectiveness of AR technology compared with traditional methods. 


\section{References}

Augmented reality. (n. d.). Retrieved from

https://www.ssatrust.org.uk/achieve ment/future/

pages/AugmentedReality.aspx

Azuma, R. T. (1997). A survey of augmented reality. Presence: Teleoperators and Virtual Environments 6(4) (August 1997), 355-385. Cambridge, MA: The MIT Press.

Billinghurst, M. $_{\text {, Kato, }} \mathrm{H}_{\text {., }}$ \& Poupyrev, I. (2001). The magic book-Moving seamlessly between reality and virtuality. IEEE Computers, Graphics and Applications, 21(3), 2-4.

Billinghurst, M. (2002). Augmented reality in education. New Horizons for Learning. Retrieved from http://www. newhorizons.org/strategi es/technology/billinghurst.htm

Chae, C., \& Ko, K. (2008). Introduction of physics simulation in augmented reality. ISUVR 2008 International Symposium on Ubiquitous Virtual Reality, 37-40.

Chang, G., Morreale, P., \& Medicherla, P. (2010). Applications of augmented reality systems in education. In D. Gibson \& B. Dodge (Eds.), Proceedings of Society for Information Technology \& Teacher Education International Conference 2010, 1380-1385. Chesapeake, VA: AACE.

Duarte, M., Cardoso, A., \& Lamounier Jr., E. (2005). Using augmented reality for teaching physics. WRA'2005 - II Workshop on Augmented Reality, 1-4.

Dünser, A., Steinbügl, K., Kaufmann, H., \& Glück, J. (2006). Virtual and augmented reality as spatial ability training tools. Proceedings of the 7th ACM SIGCHI New Zealand chapter's international conference on
Computer-human interaction: design centered $\mathrm{HCl}, 125-132$. Christchurch, New Zealand.

Fjeld, M., \& Voegtli, B. M. (2002). Augmented chemistry: an interactive educational workbench. Proceedings of the international symposium on mixed and augmented reality (ISMAR '02). Damstadt, Germany.

Freitas, R., \& Campos, P. (2008). SMART: a System of augmented reality for teaching 2nd grade students. Proceedings of the 22nd British Computer Society Conference on Human-Computer Interaction $(\mathrm{HCl}$ 2008), 27-30. Liverpool John Moores University, UK.

Henderson, J., \& Feiner, S. (2009). Evaluating the benefits of augmented reality for task localization in maintenance of an armored personnel carrier turret. Proc. Int. Symp. on Mixed and Augmented Reality (ISMAR '09), 2009, 135-144.

Johnson, L., Levine, A., Smith, R., \& Stone, S. (2010). Simple augmented reality. The 2010 Horizon Report, 2124. Austin, TX: The New Media Consortium.

Kaufmann, H. (2009). Dynamic differential geometry in education. Journal for Geometry and Graphics, 13(2), 131-144.

Kaufmann, H., \& Dünser, A. (2007). Summary of usability evaluations of an educational augmented reality application. Second International Conference, ICVR 2007. Beijing, China.

Kerawalla, L., Luckin, R., Seljeflot, S., \& Woolard, A. (2006). Making it real: Exploring the potential of augmented reality for teaching primary school science. Virtual Reality , 10(3-4), 163-174. London, United Kingdom: Springer-Verlag London Ltd. 
Kondo, T. (2006), Augmented learning environment using mixed reality technology, Proc. E-Learn, 8388.

Liarokapis, F., Mourkoussis, N., White, M., Darcy, J., Sifniotis, M., Petridis, P., Lister, P. (2004). Web3D and augmented reality to support engineering education. World Transactions on Engineering and Technology Education, 2004 UICEE Vol. 3. No. 1. Melbourne, Australia.

Schrier, K. L. (2005). Revolutionizing history education: using augmented reality games to teach histories. Master Thesis, Massachusetts Institute of Technology, Cambridge, MA.

Shelton, B. E. (2002). Augmented reality and education: Current projects and the potential for classroom learning. New Horizons for Learning. Retrieved from http://www. newhorizons.org/strategi es/technology/shelton.htm

Shelton, B. E., \& Hedley, N. R. (2002). Using augmented reality for teaching Earth-Sun relationships to undergraduate geography students. The First IEEE International Augmented Reality Toolkit Workshop. Damstadt, Germany.

Shelton, B. E., \& Hedley, N. R. (2004). Exploring a cognitive basis for learning spatial relationships with augmented reality. Technology, Instruction, Cognition and Learning, 1(4), 323-357. Philadelphia, PA: Old City Publishing, Inc.

Sutherland, I. (1968). A headmounted three-dimensional display. Proceedings of Fall Joint Computer Conference, 1968, 757-764.

Vlahakis, V., I oannidis, N., Karigiannis, J., Tsotros, M., Gounaris, M., Almeida, L., .Christou, I. (2002). ARCHEOGUIDE: First results of an augmented reality, mobile computing system in cultural heritage sites. Computer Graphics and Applications, IEEE, 52-60.

Wichert, R. (2002). A mobile augmented reality environment for collaborative learning and training. In M. Driscoll \& T. Reeves (Eds.), Proceedings of World Conference on E-Learning in Corporate, Government, Healthcare, and Higher Education 2002, 2386-2389. Chesapeake, VA: AACE.

Zhou, F., Duh, H. B. L., \& Billinghurst, M. (2008). Trends in augmented reality tracking, interaction and display: A review of ten years of ISMAR. IEEE International Symposium on Mixed and Augmented Reality, 15-18. Cambridge, UK.

Kangdon Lee has been working for Korea Occupational Safety and Health Agency (KOSHA) for 10 years as a safety consultant and an instructional material developer in Korea. Currently, Ms. Lee is a graduate student of Educational Technology at University of Northern Colorado. Ms. Lee is interested in learning and training with augmented reality, collaborative learning, and educational gaming design. 